\title{
Time-restricted eating effects on performance, immune function, and body composition in elite cyclists: a randomized controlled trial
}

Tatiana Moro ${ }^{1} \mathbb{D}$, Grant Tinsley², Giovanni Longo ${ }^{1}$, Davide Grigoletto ${ }^{1}$, Antonino Bianco ${ }^{3}$, Cinzia Ferraris ${ }^{4}$, Monica Guglielmetti ${ }^{4}$, Alessandro Veneto ${ }^{4}$, Anna Tagliabue ${ }^{4}$, Giuseppe Marcolin ${ }^{1}$ and Antonio Paoli ${ }^{* *}$

\begin{abstract}
Background: Although there is substantial interest in intermittent fasting as a dietary approach in active individuals, information regarding its effects in elite endurance athletes is currently unavailable. The present parallel randomized trial investigated the effects of a particular intermittent fasting approach, called time-restricted eating (TRE), during 4 weeks of high-level endurance training.

Methods: Sixteen elite under-23 cyclists were randomly assigned either to a TRE group or a control group (ND). The TRE group consumed 100\% of its estimated daily energy needs in an 8-h time window (from 10:00 a.m. to 6:00 p.m.) whilst energy intake in the ND group was distributed in 3 meals consumed between 7:00 a.m. and 9:00 p.m. Fat and fat-free mass were estimated by bioelectrical impedance analysis and $\mathrm{VO}_{2 \max }$ and basal metabolism by indirect gas analyzer. In addition, blood counts, anabolic hormones (i.e. free testosterone, IGF-1) and inflammatory markers (i.e. IL-6, TNF-a) were assessed.

Results: TRE reduced body weight $(-2 \% ; p=0.04)$ and fat mass percentage $(-1.1 \% ; p=0.01)$ with no change in fat-free mass. Performance tests showed no significant differences between groups, however the peak power output/body weight ratio (PPO/BW) improved in TRE group due to weight loss $(p=0.02)$. Free testosterone and IGF-1 decreased significantly ( $p=0.01$ and $p=0.03$ respectively) in TRE group. Leucocyte count decreased in ND group ( $p=0.02$ ) whilst the neutrophils-to-lymphocytes ratio (NLR) decreased significantly $(p=0.03)$ in TRE group.

Conclusions: Our results suggest that a TRE program with an 8-h feeding window elicits weight loss, improves body composition and increases PPO/BW in elite cyclists. TRE could also be beneficial for reducing inflammation and may have a protective effect on some components of the immune system. Overall, TRE could be considered as a component of a periodized nutrition plan in endurance athletes.
\end{abstract}

Trial registration: This trial was retrospectively registered at clinicaltrials.gov as NCT04320784 on 25 March 2020. Keywords: Endurance, Elite cyclists, Inflammation, Immune system, Intermittent fasting

\footnotetext{
* Correspondence: antonio.paoli@unipd.it

1 Department of Biomedical Science, University of Padova, Nutrition and Exercise Physiology Lab - Via Marzolo, 3, 35131 Padova, Italy

Full list of author information is available at the end of the article
}

(c) The Author(s). 2020 Open Access This article is licensed under a Creative Commons Attribution 4.0 International License, which permits use, sharing, adaptation, distribution and reproduction in any medium or format, as long as you give appropriate credit to the original author(s) and the source, provide a link to the Creative Commons licence, and indicate if changes were made. The images or other third party material in this article are included in the article's Creative Commons licence, unless indicated otherwise in a credit line to the material. If material is not included in the article's Creative Commons licence and your intended use is not permitted by statutory regulation or exceeds the permitted use, you will need to obtain permission directly from the copyright holder. To view a copy of this licence, visit http://creativecommons.org/licenses/by/4.0/ The Creative Commons Public Domain Dedication waiver (http://creativecommons.org/publicdomain/zero/1.0/) applies to the data made available in this article, unless otherwise stated in a credit line to the data. 


\section{Introduction}

A proper nutrition strategy is an important aspect of elite sport physical training, as nutrient availability can not only influence energy expenditure, body composition, and performance, but also the immuno-response to exercise. In the last few years, the study of intermittent fasting (IF) has gained great popularity. IF is a dietary strategy that requires individuals to totally or partially reduce caloric intake for periods that range from defined times within a day to 1-3 whole days per week. Traditionally, the most common examples of IF have been religious fasting, particularly the pattern of food abstention during Ramadan [1]. However, in the last decade, IF has been used specifically to improve body composition and health status in both healthy and obese populations [2-5].

In sports, IF is not a popular strategy and is mainly linked to those athletes that follow the Ramadan restriction, in which the caloric consumption is allowed only during nighttime with a great influence on the circadian rhythm, hormonal regulation and also thermoregulation due to a limited fluid intake [6, 7]. However, a recent meta-analysis indicated that clear detriments were not observed in most physical performance parameters during Ramadan fasting [8]. In the same study, authors remarked that reduced physical performance during Ramadan may be caused by sleep disturbance and dehydration, and that these effects seem to be more pronounced in amateur than elite athletes. Despite this, it is well known that even small differences in performance are fundamental to determine the results of elite sporting events.

Moreover, due to the intensity of training sessions, elite athletes normally undergo cycles of physiological stress, which can perturb the immune system and promote inflammation $[9,10]$. High intensity training, especially if conducted for longer than $90 \mathrm{~min}$, temporarily impairs some immune variables (i.e. lymphocyte and neutrophils counts), leading to greater risk of illness and infection $[11,12]$. In the last two decades, different strategies, including nutrition, have been tested to overcome the immunosuppressive response in athletes. Results from "immunonutrition" studies have, for example, highlighted the importance of carbohydrates and polyphenols to reduce the acute inflammatory response to exercise [13, 14]. In addition, nutrient availability can directly impact immune processes during exercise and recovery from intense exercise [15]. For instance, longterm reduction of energy intake has been associated with greater susceptibility to illness in Olympic athletes [16, 17]. Fasting has been consistently shown to reduce inflammation [18]; however, its effect on the immune system is still elusive. As reported in a recent meta-analysis [19], performing intense exercise during Ramadan results in a variation of the immunological response, but further studies are required to explore its potential regulatory role on the immune system.

Time-restricted eating (TRE) is a particular form of intermittent fasting, during which the normal period of fasting is $12-23 \mathrm{~h}$ per day. TRE can be performed with or without caloric restriction, and in the latter, individuals are allowed to consume their normal energy intake as long as they adhere to the specified window of time. We have recently demonstrated that 8 weeks of TRE does not impair muscular performance improvements in young untrained individuals performing resistance exercise training [20], can decrease fat mass and improve some health-related biomarkers (i.e. IL-6, TNF- $\alpha$, Insulin, HDL-C, TG) in resistance-trained males [21], and does not impair lean mass gain or performance improvements in resistance-trained females [22].

To our knowledge, there is no evidence regarding the effect of TRE on endurance sports or the impact that this type of diet can have on the immune system. In endurance sports such as cycling, the power/weight ratio is a very important physical indicator for the athlete. The power expressed by an athlete reflects the speed of the race or the ability to climb a greater slope at the same speed. On the other side, lower body weight of the athlete can be an advantageous factor considering that a lighter cyclist spends less energy to maintain the same speed and therefore gets less tired; or, as climbing is the true essence of this sport, a lighter athlete should be faster during a climb. It therefore seems plausible that a dietary approach that allows weight loss, while maintaining the muscle functional characteristics, could be a winning strategy for endurance athletes. The aim of this study was to investigate the effects of 4 weeks of TRE, with a daily $16-\mathrm{h}$ fast and 8 -h feeding window, in a group of young elite cyclists. We hypothesized that TRE would reduce inflammatory markers and fat mass without affecting physical performance.

\section{Methods}

Sixteen healthy young men (age: $19.3 \pm 0.1$ years; weight: $69.66 \pm 6.11 \mathrm{~kg}$; fat mass: $11.16 \pm 1.99 \mathrm{~kg}$ ) were recruited from 5 different elite cyclist teams from the Veneto region in Italy and randomly assigned to a time-restricted eating group (TRE; $n=8$ ) or a standard diet group (ND; $n=8$ ) using a computer-generated software. To be included in the study, subjects must have been cycling for at least three seasons in an elite team. Exclusion criteria were recent injuries, usage of steroids or corticosteroids or any other medical condition that could interfere with study procedures. Subjects characteristics for each group are described in Table 1. All the participants read and signed an informed consent form describing all the study procedures approved by the ethical committee of the 
Table 1 Subjects characteristics

\begin{tabular}{lll}
\hline & TRE $(\boldsymbol{N}=\mathbf{8})$ & ND $(\boldsymbol{N}=\mathbf{8})$ \\
\hline Age (years) & $19.38 \pm 2.39$ & $19.38 \pm 1.60$ \\
Body weight $(\mathrm{kg})$ & $67.04 \pm 5.03$ & $72.27 \pm 6.24$ \\
Height $(\mathrm{cm})$ & $175.0 \pm 4.82$ & $179.1 \pm 5.83$ \\
BMl $\left(\mathrm{kg} / \mathrm{m}^{2}\right)$ & $21.85 \pm 1.65$ & $22.47 \pm 1.83$ \\
Fat mass $(\mathrm{kg})$ & $10.78 \pm 1.40$ & $11.53 \pm 2.24$ \\
Fat free mass $(\mathrm{kg})$ & $56.26 \pm 4.93$ & $60.74 \pm 5.72$ \\
Training Km on previous season & $13,500 \pm 1500$ & $13,000 \pm 1500$ \\
\hline
\end{tabular}

Data are presented as mean \pm SD

Department of Biomedical Sciences, University of Padova, and conformed to standards of the current Declaration of Helsinki. Study analysis was conducted in a single blind design at the University of Padova.

\section{Experimental design}

The experimental design is displayed in Fig. 1. All participants were tested on two different days before and at the end of the 4-week experiment. All participants started the experimental procedures in the month of January 2019.

Subjects reported to the laboratory after $12 \mathrm{~h}$ fasting, approximately between 7 and 9 am, and were asked to abstain from caffeine, alcohol consumption and from vigorous physical activity for $24 \mathrm{~h}$ prior to each measurement. Subjects were also asked to keep the same routine of dinner before each visits. At their arrival, body weight and height were measured and used to calculate body mass index (BMI). Fat mass (FM) and fat-free mass (FFM) were assessed by Bioelectrical Impedance Analysis (Human in Touch, DSMedica, Milano). Test-retest reliability for body composition obtained in our laboratory had an ICC of 0.99 , consistent with previous findings [23]. Subjects were asked to lie down and rest for 10 min, whilst two electrodes were placed on their wrists and ankles. Through the analysis software, we obtained the values of FFM and FM.

Resting energy expenditure (REE) and oxygen uptake $\left(\mathrm{VO}_{2}\right)$ were measured via a standard open-circuit calorimetry (max Encore 29 System, Vmax, Viasys Healthcare, Inc., Yorba Linda, CA, USA) on a breath-by-breath modality and estimated by the modified Weir equation as previously described $[21,24]$. Participants rested in the supine position on a comfortable surface and stayed awake for the entire test duration. Following the application of a silicone mask that covered both mouth and nose, oxygen and carbon dioxide concentrations were obtained for a total of $20 \mathrm{~min}$. Only the last $10 \mathrm{~min}$ were used to measure the results.

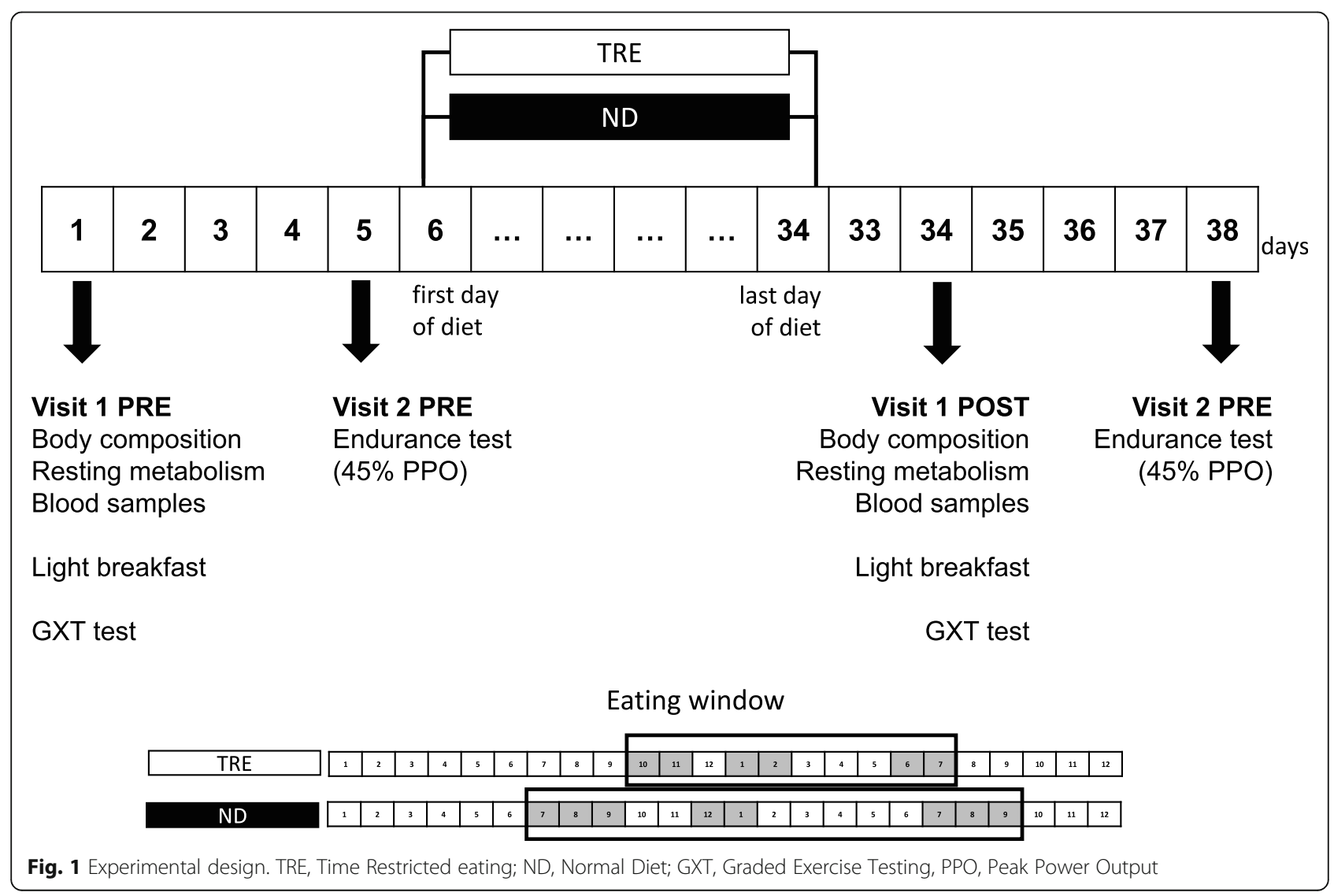


When the ventilatory test was completed, blood samples were collected from the antecubital vein, then aliquoted and stored at $-80^{\circ} \mathrm{C}$ after proper centrifugation until analysis. All samples were analyzed by a certified laboratory using the same reagent lot. Complete blood count, total cholesterol, high-density lipoprotein cholesterol (HDL-C), low-density lipoprotein cholesterol (LDL-C), triglycerides (TG) were measured via enzymatic colorimetry (Modular D2400, Roche Diagnostics, Basel, Switzerland), insulin value was obtained with a chemiluminescent immunoassay (Siemens Immulite 2000), glucose was measured using the glucose oxidase method (glucose analyzer, Beckman Instruments, Palo Alto, CA, USA), interleukin-6 (IL-6), tumor necrosis factor- $\alpha$ (TNF- $\alpha$ ) and interleukin- $1 \beta$ (IL-1 $\beta$ ) were measured via Quantikine HS Immunoassay Kit (R\&D Systems, Minneapolis, MN, USA), whilst insulin-like growth factor 1 (IGF-1) plasma concentrations were measured using the analyzer Liaison XL (DiaSorin S.p.A, Vercelli-Italy).

Thereafter, all subjects consumed a standard light breakfast of $\sim 350-450 \mathrm{kcal}$ mainly composed of carbohydrates. The exact same breakfast was provided during the post test. Approximately $45 \mathrm{~min}$ after breakfast, subjects performed an incremental maximal test (GXT) on a bike, in which peak power output (PPO; max watt maintained for at least $30 \mathrm{~s}), \mathrm{VO} 2(1 / \mathrm{min}), \mathrm{VO} 2 \max$ $(\mathrm{ml} / \mathrm{kg} / \mathrm{min})$, carbon dioxide production $(\mathrm{VCO} 2 ; 1 / \mathrm{min})$ and respiratory ratio (RR) were measured. Each athlete used personal shoes with Kéo pedals; the height of the saddle has been positioned at the maximum level of comfort for each athlete and for the subsequent tests the same relative measure was always used. Heart rate was recorded every $30 \mathrm{~s}$, with a Polar band heart rate monitor (Kempele, Finland). After applying a silicone mask to the face for the analysis of respiratory gases, subjects started the test. The protocol included: $1 \mathrm{~min}$ of warm up at $60 \mathrm{~W}$, then $1 \mathrm{~min}$ at $100 \mathrm{~W}$, after which intensity increased by $30 \mathrm{~W}$ every $60 \mathrm{~s}$ until exhaustion.

Three to 4 days later, subjects performed an endurance test at $45 \%$ of the previously calculated PPO to measure the same ventilatory parameters. This test was chosen because it represents the exercise intensity normally registered during a long-distance race. Subjects were asked to cycle for $45 \mathrm{~min}$ at $45 \%$ of their PPO while respiratory gas analysis, $\mathrm{VO} 2(\mathrm{l} / \mathrm{min}), \mathrm{VO} 2 \mathrm{max}(\mathrm{ml} / \mathrm{kg} / \mathrm{min})$, VCO2 (l / min), RR were obtained by the same gas analyzer used in visit 1 . In addition, heart rate (HR) was collected at each minute of the test. Each athlete was asked to refrain from intense training on the day before the test and to consume a light and simple meal $2 \mathrm{~h}$ before the test. On average, subjects consumed approximately $350-450 \mathrm{kcal}$ with a prevalent carbohydrate content $(\sim 50-80 \mathrm{~g})$; specifically, a light breakfast of bread, jam, and fruit juice was provided. In order to reproduce the same conditions, all meals were recorded and repeated 28 days later during the POST test.

At the end of the second visit, all subjects received their diet protocol, and the study intervention officially started the following day. All laboratory testing procedures were repeated in the same order after 4 weeks of the intervention.

\section{Diet}

During the recruitment phase, all subjects completed a validated 7-day food diary for athletes [25] which was analyzed by nutritional software (Dieta Ragionata 7.0) to estimate individual daily dietary intake. Based on the results from the food diary and specific energy and macronutrients requirements for athletes [26, 27], all athletes received the same 7 -day diet plan, in which the caloric intake was set at $4800 \mathrm{kcal}$. The intervention dietary plan did not significantly differ from the athlete's baseline regimen in terms of macronutrient intake, but the two intervention groups differed in the time window in which they consumed their meals (Table 2). Before starting the trial, all participants reported consuming all meals between 7 and 9 am and 7-9 pm each day. The team dietitian supervised most of the meals consumed and ensured that all participants followed the prescribed diet intervention.

The TRE group was instructed to consume $100 \%$ of their caloric intake divided in four eating occasions consumed in a time window of $8 \mathrm{~h}$, with the three major meals distributed as follows: breakfast (10-11 a.m.), lunch (1-2 p.m.), dinner (6-7 p.m.). The ND group ingested their energy intake according to a traditional pattern, with breakfast between approximately 7-9 a.m., lunch at 12-1 p.m. and dinner between 7 and 9 p.m. Both groups consumed their snack either before or after the daily training session. Every week, a dietitian contacted subjects in order to check the adherence to the diet protocol.

\section{Training}

The study was conducted during the winter precompetition season. As such, most of the training consisted of long outings at a mild/medium pace at the steady state. The training schedule included $500 \pm 50$ $\mathrm{km} /$ week divided into 6 sessions per week that took place within the feeding time window (10 a.m.-6 p.m.).

\section{Statistical analysis}

Statistical analyses were performed using the statistical software GraphPad Prism version 7.00 for Mac OS X (GraphPad Software). Target sample size was obtained assuming an interaction of a Root Mean Square Standardized Effect (RMSSE) of 0.25 with a fixed power of $80 \%$ and an alpha risk of $5 \%$ for the primary outcomes. 
Table 2 Diet composition and macronutrients distribution

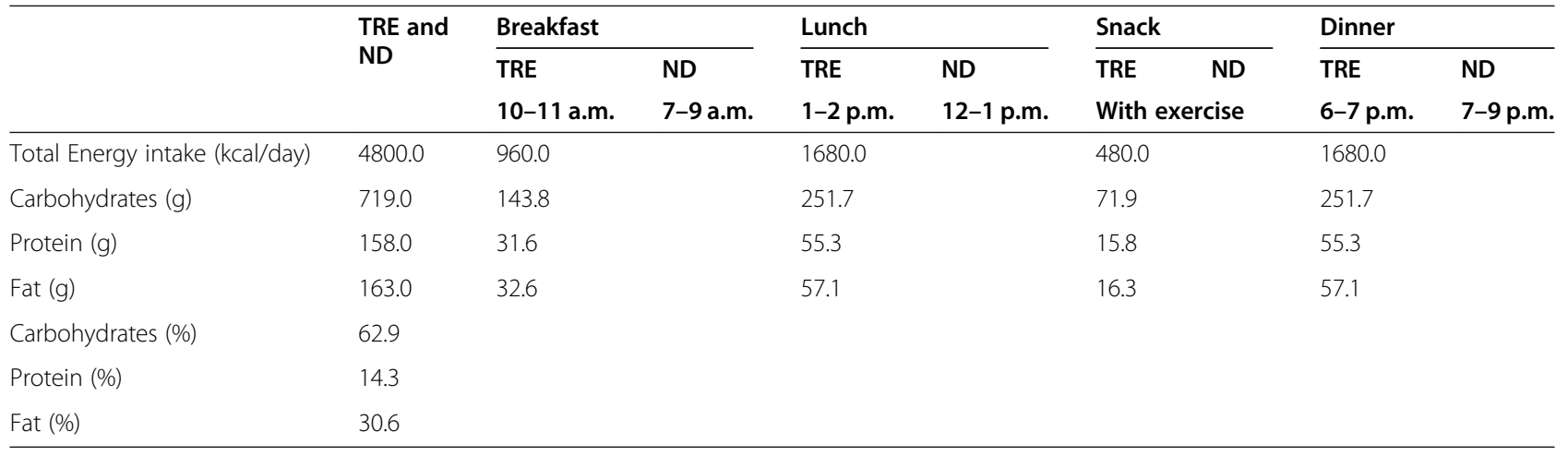

Kcal for each macronutrient was calculated considering $3.5 \mathrm{kcal} / \mathrm{g}$ for protein, $3.75 \mathrm{kcal} / \mathrm{g}$ for carbohydrates and $9 \mathrm{kcal} / \mathrm{g}$ for fat

TRE time restricted eating, ND normal diet

Primary outcomes for the power analysis were $\mathrm{VO}_{2} \max$, fat and fat-free mass. After assessing the normal distribution through the Shapiro-Wilk's W test, an independent samples t-test was used to test baseline differences between groups. A two-way repeated-measures ordinary ANOVA was performed (using time as the withinsubject factor and diet as the between-subject factor) in order to assess differences between groups over the course of the study. When the ANOVA model produced significant main or interaction effects, Post-hoc analyses were performed using the Bonferroni test. All differences were considered significant at $P<0.05$.

\section{Results}

\section{Body composition}

After 4 weeks, a significant time $\mathrm{x}$ diet interaction $(p=$ $0.04)$ was observed in total body weight: the TRE group experienced a significant $(p=0.03)$ decrease total body mass of $\sim 2 \%$ (from $67.04 \pm 5.03$ to $65.78 \pm 4.93 \mathrm{~kg}$ ) while no significant change was observed in the ND group (from $72.28 \pm 6.24$ to $72.50 \pm 6.45 \mathrm{~kg}$ ). This alteration appeared to be mainly due to a decrease in total body fat mass. Although there was not a significant interaction, we observed a significant main effect of diet $(p=0.01)$ for the fat mass outcome. Relative fat mass decreased by $\sim 11 \%$ (from $9.59 \pm 0.77$ to $8.52 \pm 1.21 \%$ ) in the TRF group but increased by $\sim 4 \%$ (from $10.65 \pm 2.24$ to $10.77 \pm 0.97 \%$ fat mass) in the ND group, although these changes were not statistically significant. Fat-free mass was maintained in both groups (TRE from $56.26 \pm 4.93$ to $56.15 \pm 5.05 \mathrm{~kg}$; ND from $60.74 \pm 5.72$ to $60.72 \pm 7.37$ kg) (Fig. 2).

\section{Resting metabolism}

No statistically significant interaction was found for resting metabolism analysis. Resting energy expenditure (REE) calculated by Weir [24] equation decreased in both groups (main time effect $p=0.054$; main diet effect $p=0.060)$ and to an apparently greater extent after the TRE diet $(\sim-10 \%)$ compared to ND diet $(\sim-2 \%)$. The analysis of ventilatory parameters showed a decrease of $\mathrm{VO}_{2}$ of about $10 \%$ in the TRE group $(p=0.07)$ and $4 \%$ in the ND group $(p>0.05)$. Similar results were obtained when $\mathrm{VO}_{2}$ was normalized by body weight (Table 3 ).

\section{Performance test}

No significant differences were observed between groups in any of the performance test outcomes. Absolute PPO

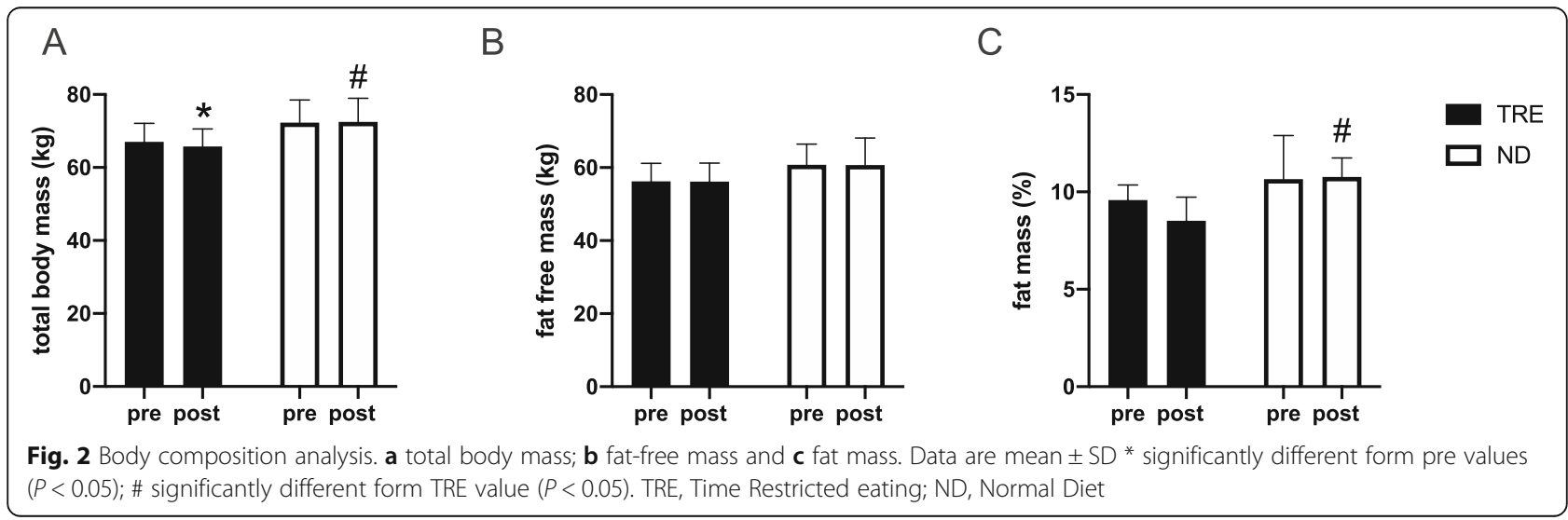


Table 3 Ventilatory measurement during resting, incremental and endurance test

\begin{tabular}{|c|c|c|c|c|c|c|c|}
\hline & \multicolumn{2}{|l|}{ TRE } & \multicolumn{2}{|l|}{ ND } & \multirow{2}{*}{$\begin{array}{l}2 \text { Way } \\
\text { ANOVA } \\
\text { Time * diet }\end{array}$} & \multirow{2}{*}{$\begin{array}{l}\text { Main time } \\
\text { effect }\end{array}$} & \multirow{2}{*}{$\begin{array}{l}\text { Main diet } \\
\text { effect }\end{array}$} \\
\hline & Pre & Post & Pre & Post & & & \\
\hline \multicolumn{8}{|l|}{ Resting metabolism } \\
\hline REE (Kcal/day) & $1992 \pm 251$ & $1772 \pm 147$ & $2075 \pm 273$ & $2005 \pm 109$ & ns & 0.054 & ns \\
\hline $\mathrm{VO}_{2}(\mathrm{I} / \mathrm{min})$ & $0.28 \pm 0.04$ & $0.25 \pm 0.02$ & $0.30 \pm 0.04$ & $0.28 \pm 0.02$ & ns & 0.031 & ns \\
\hline $\mathrm{VO}_{2} / \mathrm{kg}(\mathrm{ml} / \mathrm{kg} / \mathrm{min})$ & $4.18 \pm 0.49$ & $3.87 \pm 0.46$ & $4.05 \pm 0.37$ & $3.87 \pm 0.43$ & ns & ns & ns \\
\hline \multicolumn{8}{|c|}{ Graded exercise testing (GXT) } \\
\hline $\mathrm{VO}_{2}(1 / \mathrm{min})$ & $4.83 \pm 0.53$ & $4.59 \pm 0.56$ & $4.90 \pm 0.25$ & $4.85 \pm 0.26$ & ns & ns & ns \\
\hline $\mathrm{VO}_{2} / \mathrm{kg}(\mathrm{ml} / \mathrm{kg} / \mathrm{min})$ & $71.98 \pm 3.93$ & $69.94 \pm 8.66$ & $68.30 \pm 7.19$ & $67.17 \pm 4.59$ & ns & ns & ns \\
\hline $\mathrm{VCO}_{2}(1 / \mathrm{min})$ & $5.78 \pm 0.49$ & $5.44 \pm 0.60$ & $6.01 \pm 0.39$ & $5.71 \pm 0.30$ & ns & 0.028 & ns \\
\hline $\mathrm{RR}$ & $1.19 \pm 0.05$ & $1.19 \pm 0.05$ & $1.23 \pm 0.04$ & $1.18 \pm 0.03$ & ns & ns & ns \\
\hline PPO (watt) & $407.50 \pm 41.66$ & $415.00 \pm 39.28$ & $411.25 \pm 35.63$ & $403.75 \pm 29.73$ & ns & ns & ns \\
\hline PPO/BW (watt/kg) & $6.08 \pm 0.51$ & $6.31 \pm 0.46$ & $5.71 \pm 0.55$ & $5.60 \pm 0.53$ & 0.024 & ns & 0.045 \\
\hline $\mathrm{HR}(\mathrm{bpm})$ & $196.13 \pm 9.99$ & $190.63 \pm 12.39^{*}$ & $190.88 \pm 12.33$ & $182.38 \pm 10.07^{*}$ & ns & 0.0001 & ns \\
\hline \multicolumn{8}{|c|}{ Endurance test (45\% PPO) } \\
\hline $\mathrm{VO}_{2}(1 / \mathrm{min})$ & $2.95 \pm 0.16$ & $3.05 \pm 0.38$ & $3.00 \pm 0.25$ & $3.25 \pm 0.56$ & ns & ns & ns \\
\hline $\mathrm{VO}_{2} / \mathrm{kg}(\mathrm{ml} / \mathrm{kg} / \mathrm{min})$ & $44.14 \pm 2.68$ & $46.13 \pm 4.67$ & $41.74 \pm 4.53$ & $45.11 \pm 8.69$ & ns & ns & ns \\
\hline $\mathrm{VCO}_{2}(1 / \mathrm{min})$ & $2.80 \pm 0.19$ & $2.90 \pm 0.37$ & $2.80 \pm 0.31$ & $2.94 \pm 0.05$ & ns & ns & ns \\
\hline RR & $0.97 \pm 0.04$ & $0.96 \pm 0.06$ & $0.93 \pm 0.05$ & $0.91 \pm 0.07$ & ns & ns & 0.053 \\
\hline HR (bpm) & $157.13 \pm 16.86$ & $149.00 \pm 13.14^{*}$ & $158.13 \pm 18.53$ & $146.13 \pm 14.46^{*}$ & ns & 0.0002 & ns \\
\hline
\end{tabular}

Results are presented as mean \pm SD

TRE time restricted eating, ND normal diet

* Significantly different from pre values $(p<0.05)$; \# significantly different from TRE group $(p<0.05)$; ns $(p>0.05)$

wasn't affected by training or diet; however the PPO/BW ratio presented a significant time $\mathrm{x}$ diet interaction $(p=$ $0.02)$, with a main effect of diet $(p=0.04)$ also observed; compared to the baseline value, the TRE group increased the ratio by $4 \%(p=0.06)$ whilst ND decreased this ratio by $2 \%(p=0.44)$, which leaded to a significant difference between groups $(p=0.02)$ in the post intervention values. Maximal heart rate achieved during the test equally decreased ( $p<0.05$ for time main effect) in both groups (TRE $-3 \%, p=0.02$; ND $-4 \%, p=0.001$ ). Similarly, during the endurance test performed at $45 \%$ of $\mathrm{PPO}, \mathrm{VO}_{2}, \mathrm{VCO}_{2}$ and the RR remained unaltered whilst HR significantly decreased in both groups (TRE $-5 \%$, $p=0.02$; ND $-7 \%, p=0.002$ ) (Table 3).

\section{Blood analysis}

Data from blood biochemistry analysis are presented in Table 4. Creatinine showed a significant time effect $(p=$ 0.007 ) with a slight decrease of $\sim 3 \%$ in the TRE group and a significant $(p=0.03)$ decrease of $5 \%$ after 4 weeks of ND. Ferritin was unaltered in the TRE group $(+5 \%$, $p>0.05)$ whilst apparently decreased in the ND group $(-23 \%, p=0.053)$, although the time by diet interaction was not statistically significant.

The hormonal profile showed significant time $\mathrm{x}$ diet interaction $(p=0.01)$ in the levels of T3 free in which a slight decrease of $\sim 6 \%$ was noted in the TRE whilst ND increased by $\sim 9 \%(p=0.07)$. Free testosterone decreased in both groups (main time effect $p=0.005$; diet effect $p=0.05$ ) but was significantly lower from baseline value only in the TRE group $(-27 \%, p=0.006)$, such that at the post training time point, the two groups significantly differed ( $p=0.03$ TRE vs ND). We observed a trend in time $\mathrm{x}$ diet interaction $(p=0.07)$ in IL-6 value, with no change from baseline in the TRE group $(-3 \%)$ and a trend to increase after ND $(+28 \%)$. On the contrary, adiponectin levels tended to increase $(+33 \%, p=0.08)$ after TRE diet whilst a lesser effect was noted in the ND group $(+8 \%, p>0.05)$. When adiponectin levels were normalized by body fat mass the differences showed an almost significant time $\mathrm{x}$ diet effect $(p=0.058)$, with TRE increasing by $50 \%(p=0.02)$ and ND by $5 \%(p>$ $0.05)$. IGF-1 significantly decreased only in the TRE group $(-12 \%, p=0.03)$ whilst no change was observed in the ND group $(+3 \%, p>0.05)$; as such we detected a trend to significance in time $\mathrm{x}$ diet interaction $(p=0.06)$.

Leucocytes decreased in both groups (main time effect $p=0.001$ ), but the difference between baseline and final values was only significant for ND $(-21 \%, p=0.02$ vs TRE $-14 \%, p>0.05)$. The percentage of neutrophils significantly decreased by $\sim 12 \%$ in both groups $(p<0.05)$, whilst lymphocytes increased by $\sim 34 \%$ in the TRE group 
Table 4 Blood biochemestry results

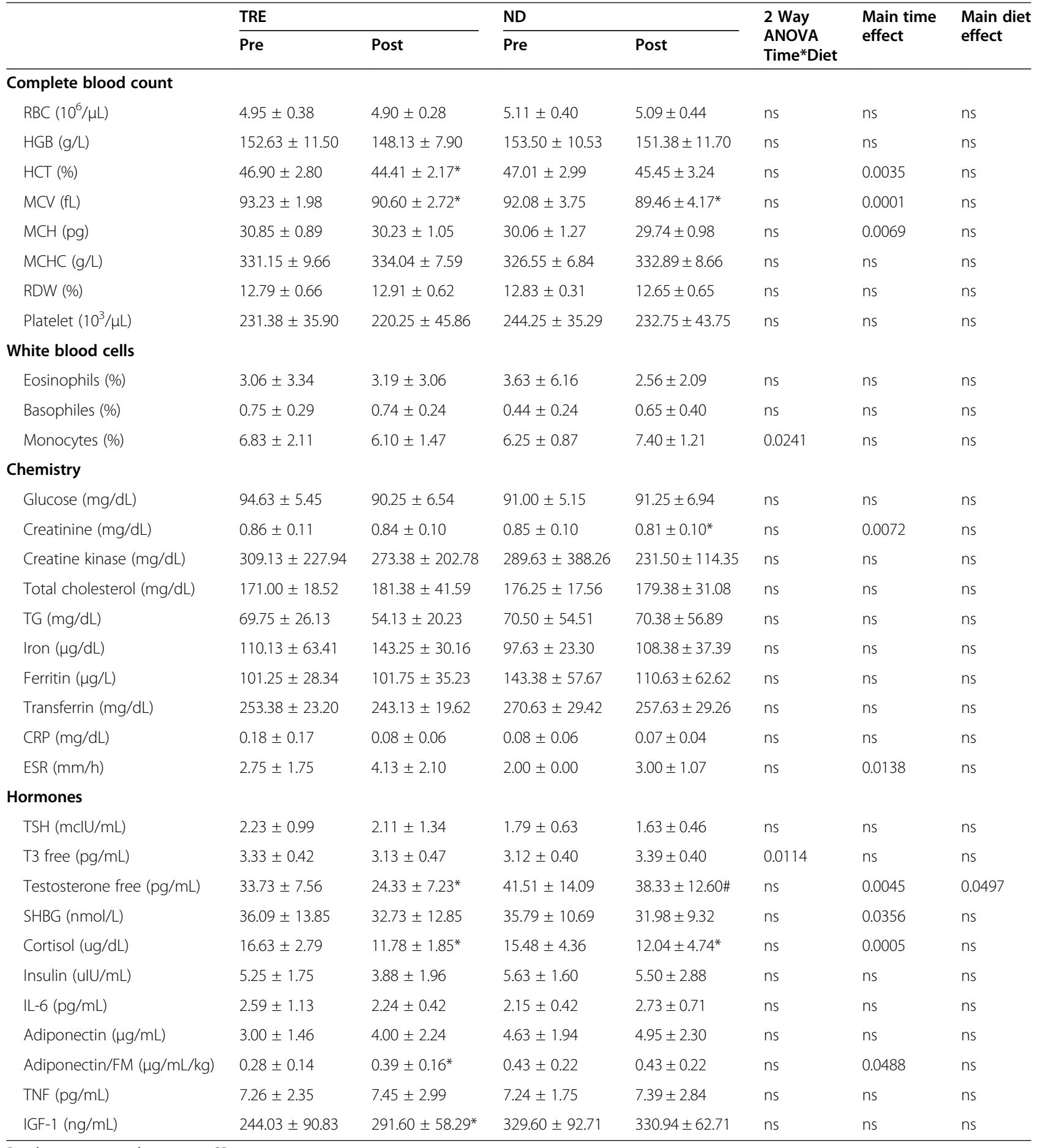

Results are presented as mean \pm SD

TRE time restricted eating, ND normal diet

* Significantly different from pre values $(p<0.05)$; \# significantly different from TRE group $(p<0.05)$

( $p=0.0004)$ and by $\sim 27 \%$ in the ND group $(p=0.001)$. As a result, the Neutrophils-to-Lymphocytes ratio (NLR) decreased in both groups but was significantly different from baseline value only in the TRE group $(p=0.03)$ (Fig. 3).

\section{Discussion}

TRE is a particular intermittent fasting approach in which the total daily caloric intake is often not reduced but distributed in a different frequency of meals, with the normal duration of eating ranging from 1 to $4 \mathrm{~h}$ to 
A

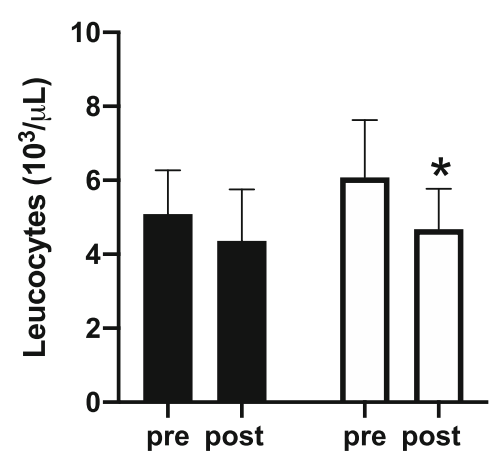

C

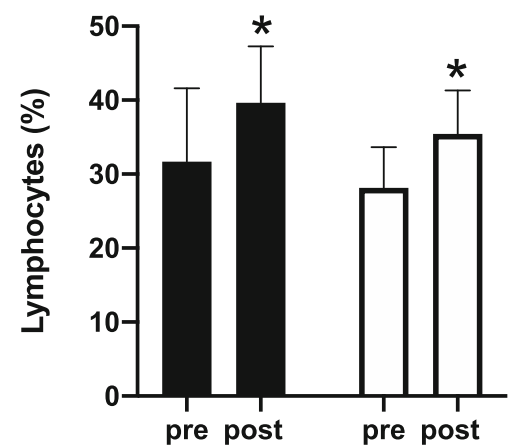

B

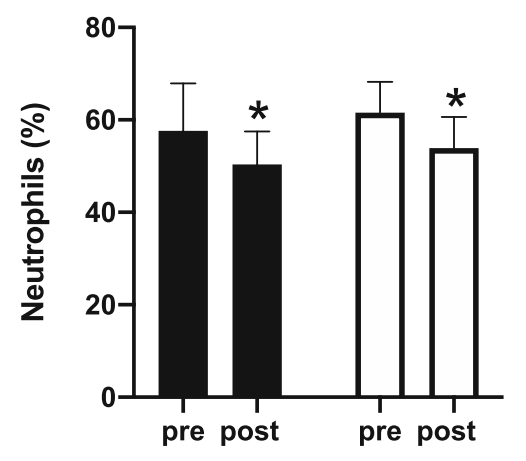

D

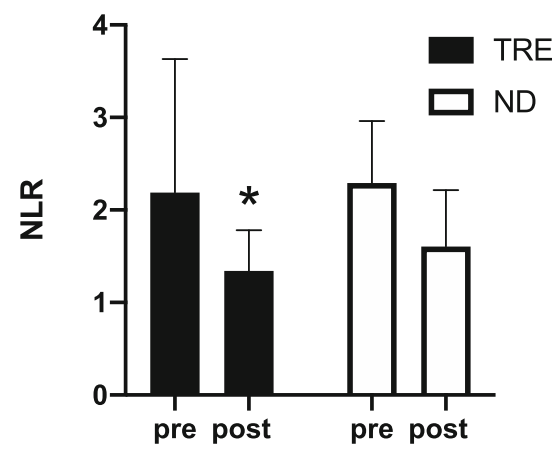

Fig. 3 White blood cells response to 4 weeks of treatment. a White Blood Cells; b Neutrophils; c Lymphocytes and $\mathbf{d}$ Neutrophils-to-Lymphocytes ratio (NTR). Data are mean $\pm S D$ * significantly different form pre values $(P<0.05)$. TRE, Time Restricted eating; ND, Normal Diet

10-12 h. In sports, intermittent fasting studies have mostly focused on Muslim athletes during the Ramadan period, a practice that requires abstention from food and liquid throughout the day and consumption of meals at night $[6,7]$. To our knowledge, this is the first study that has investigated the effect of TRE in a group of elite endurance athletes. Our data demonstrated that during 4 weeks of pre-season training, TRE allows for maintenance of fat-free mass and reduction of fat mass, promoting a diminution of total body weight. We confirm that TRE reduced anabolic hormones (such as IGF-1 and testosterone) without affecting fat-free mass or endurance sport performance. In addition, it seems that TRE may exert a protective effect on some aspects of the immune system in the context of exercise training.

\section{Body composition}

The TRE employed in this study was a $16 / 8$ modality and consisted in $16 \mathrm{~h}$ fasting and $8 \mathrm{~h}$ feeding. We have recently demonstrated that the same TRE protocol used with resistance-trained athletes reduced total body weight and fat mass [21]. In the present study, we confirmed the positive effect of TRE on body composition. Total energy and nutrient intake were comparable between groups; for these reasons one possible explanation of the greater weight loss in the TRE group could be found in the increase in adiponectin. Adiponectin stimulates PGC- $1 \alpha$ expression and mitochondrial biogenesis through the AMPK kinase [28], stimulating adipogenesis. Lower levels of adiponectin are associated with obesity [29] and oxidative stress [30]; whilst elevated plasma concentration of this cytokine correlates with improved metabolism and resting energy expenditure [28, 31]. We have previously demonstrated that adiponectin levels increase after 8 weeks of TRE compared to a normal diet; and these results correlated with weight loss [21]. In the present study, the levels of adiponectin tended to increase $(+33 \%)$ after TRE compared to a blunted response in the ND group $(+8 \%)$. When data were normalized relative to body fat mass, the apparent difference was even more pronounced (TRE + 50\%; ND + 5\%). Thus, TRE seems to induce a rise in adiponectin which may contribute to the reduction in body fat observed after 4 weeks of treatment. We have however observed a reduction in REE after TRE diet, which might seem a counterproductive adaptation. A decrease in REE is a common result of weight loss programs that involve calorie restriction, and it normally correlates with a loss of FFM and especially to changes in its composition [32, 33]. However, these studies are normally conducted in 
obese or overweight subjects not involved in any strenuous exercise program. In the present study, FFM was maintained and thus cannot explain the observed reduction in REE. It is, however, possible that this reduction reflects a momentaneous thermogenic adaptation of body weight, as described by the mechanical model of Rosenbaum and Leibel [34], in which REE decreases with initial weight loss. It is possible that in athletes, in which body fat is very low, and the exercise energy expenditure is particularly high, even a small drop of body weight (i.e 2-3\%) may perturbate energy homeostasis. It is also possible that during TRE protocol, subjects have slightly reduced their caloric intake, which might have increased the negative energy balance and reduced REE. Each participant was strictly supervised by the personal team dietitian which ensured the adherence to diet protocol in terms of feeding window and caloric intake. Unfortunately, we have not recorded the post treatment dietary assessment to confirm or exclude this possibility.

Another explanation through which TRE may have improved body composition is linked to circadian clocks. The circadian control of food intake is situated in the hypothalamus which is synchronizes to the solar lightdark cycle. At the molecular level, the actions of specific genes (BMAL1, CLOCK) are deputed to control the cellautonomous circadian rhythms. However, fasting and feeding alternation can directly impact daily circadian rhythms through the activation of mTOR, AMPK, CREB, and AKT, which are key regulators of metabolism and nutrient homeostasis [35]. A proper arrangement of nutrient intake and abstention can thus severely influence body metabolism. In a recent study, Yasumoto et al. [36] showed that a wrong pattern of feeding/fasting can desynchronize peripheral clocks inducing obesity and metabolic disorders in mice. It is plausible to assume that in our study, in which TRE subjects were forced to eat between $10 \mathrm{am}$ and 7 p.m., the timing of feeding was well synchronized with the light-dark cycle and therefore may have positively impacted body metabolism. Unfortunately, we haven't directly assessed the genes linked to the circadian clock, and further study should be employed to confirm this hypothesis.

\section{Aerobic performance and metabolism}

In elite cyclists, the relation between PPO and body weight is an important contributing factor to sport performance. Overall, the performance during the incremental and endurance test did not change from baseline; however, we observed a significant increase of $\mathrm{PPO} / \mathrm{BW}$ in the TRE group as compared to the ND group. It is interesting to note that fat-free mass wasn't compromised during the diet regimen, even though TRE induced a reduction of testosterone and IGF-1. We have previously observed a drop of anabolic hormones after TRE [21], probably due to a reduced leptin-mediated control on the hypothalamo-hypophysial-gonadal axis. It seems indeed that intermittent fasting regimen can exert an inhibitory effect on the Leydig cells responsible for the production of testosterone [37, 38]. Moreover, it is possible that TRE, similarly to calorie restriction, stimulates the AMP-activated protein kinase/Acetyl-CoA-Carboxylase (AMPK/ACC) signaling pathway [3]. AMPK is a central metabolic regulator activated during low cellular energy status, when trigged it stimulates ATP production via fatty acid oxidation and glycolysis, while simultaneously inhibits anabolic processes. Studies performed in rodents, showed that short-term fasting $(19-39 \mathrm{~h})$ increases AMPK and ACC activation in adipocytes, but not in muscle [39, 40]; however, this hypothesis hasn't been confirmed in humans. Moreover, caloric restriction doesn't seem to reduce IGF-1 concentration, although it may increase IGFBP-1 [41]. In the present study we did not analyze plasma leptin but considering the similarity between the TRE protocol and our prior study in resistance-trained men, we can speculate that the reduction of anabolic hormones could be due to an alteration of adiponectin/leptin levels.

Unlike our previous study [21] on resistance-trained athletes, we didn't observe any significant alteration of T3 nor TSH levels or REE in the TRE group. Interestingly, ferritin appeared to decrease in ND but not in TRE, although this was not statistically significant. Ferritin not only reflects iron stores but is also used as an index of exercise tolerance $[42,43]$. A drop of ferritin in endurance athletes can occur during the initial months of training [44], although TRE seems to blunt this effect.

\section{Inflammatory markers and immune response}

Endurance elite athletes present lower leucocytes counts, neutrophils and monocytes plasma concentration compared to other sports, probably due to the inflammatory adaptive response to aerobic training [45]. These decreases in components of the immune system may contribute to the susceptibility to bacterial and upper respiratory infection [46, 47]. Exercise increases proinflammatory cytokines (such as IL-6, IL-1 $\beta$; TNF- $\alpha$ ), which mediate the communication between immune and non-immune cells in order to elicit repair processes. This activation is transient, with markers normally returning to basal level in 24-30 h [48], and is followed by the release of anti-inflammatory cytokines that have the function to reduce the inflammatory process [49, 50]. As a result, the immune response temporarily decreases, with total leucocytes and neutrophils increasing whilst lymphocytes decrease. We already reported a modulation of some inflammatory markers after TRE (IL-6 and IL-1 $\beta$ and TNF- $\alpha$ ) [21], whilst others did not observe any changes of these cytokines in healthy young men [51]. In the present study, IL-6 appeared to 
decrease in TRE and increase in ND (even if not significantly). Moreover, the ratio of neutrophils-to-lymphocytes (NLR) is a biomarker of systemic inflammation largely used in clinical practice, which correlates with the circulating level of C-reactive protein (CRP) [52, 53]. In our study, both groups presented a decrease in neutrophils and an increase in lymphocytes after 4 weeks of treatment, whilst the NLR seems to be more affected by the TRE compare to ND (TRE -39\%; ND - 30\%). Interestingly, while post-intervention leucocytes appeared lower than baseline in both groups, they were significantly reduced only in the ND group. It is known that short-term caloric restriction can compromise the immune system response $[15,54]$, however, the present experiment did not reduce the energy intake. This is the first time that TRE has been correlated to the immune response to exercise training, and it seems that TRE may possibly have a protective effect, attenuating the reduction in leucocytes count and thus potentially preventing the susceptibility to infections in young elite endurance athletes.

Some limitations of the present study should be taken into account. One is the reduced number of subjects involved, and secondly the usage of an interview methodology to determine energy and macronutrient composition. This approach has known weaknesses and may have played a role in the observed outcomes. Moreover, although the team dietitian supervised most of the meals consumed, we didn't collect a food diary record during the intervention to compare with the baseline habits.

\section{Conclusion}

Our results suggest that the 16/8 TRE protocol could be beneficial in elite endurance athletes to improve body composition and inflammatory markers without affecting aerobic performance. Moreover, TRE may help the function of the immune system, attenuating the decrease of leucocytes that typically occurs in high-trained individuals, although further investigation is warranted. This kind of dietary regimen could be adopted by endurance athletes to reduce body fat mass. Our preliminary data may suggest that TRE could be a proper dietary regimen in particular during the pre-season training that normally occurs during the winter season, in which the training-induced depression of immune system increases the respiratory infection susceptibility.

\footnotetext{
Abbreviations

ACC: Acetyl-CoA-Carboxylase; AKT: Protein kinase B; AMPK: 5' AMP-activated protein kinase; BMAL1: Brain and Muscle ARNT-Like 1; BMI: Body Mass Index; BW: Body weight; CLOCK: Basic helix-loop-helix-PAS transcription factor; CREB: CAMP response element-binding protein; CRP: C-reactive protein; FFM: Fat Free Mass; FM: Fat Mass; HDL-C: High-Density Lipoprotein Cholesterol; ICC: Inter class correlation; IF: Intermittent fasting; IGF-1: Insulinlike growth factor 1; IGFBP-1: Insulin-like growth factor Binding protein 1; IL-

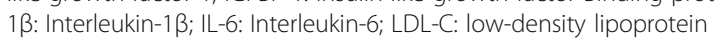
cholesterol; mTOR: Mammalian target of rapamycin; ND: Normal Diet; NRL: Neutrophils-to-Lymphocytes ratio; PGC-1a: Peroxisome proliferator-
}

activated receptor gamma coactivator 1-alpha; PPO: Peak Power Output; REE: Resting energy expenditure; T3: Triiodothyronine; TG: Triglycerides; TNFa: Tumor necrosis factor-a; TRE: Time Restricted Eating; TSH: Thyroidstimulating hormone; VO2: Oxygen uptake

\section{Acknowledgments \\ Not applicable.}

\section{Authors' contributions}

TM, GT, GM, AB and AP contributed substantially to the study design, data analysis and interpretation, and the writing of the manuscript. GL and DG collected data; CF, MG, AV, AT designed, prescribed and analyzed nutritional plans. All authors approved the final version of the manuscript and agree to be accountable for all aspects of the work.

\section{Funding}

The study has been carried out as part of institutional research activity and there are no financial reasons which may lead to a conflict of interest.

\section{Availability of data and materials}

The datasets during and/or analysed during the current study available from the corresponding author on reasonable request.

\section{Ethics approval and consent to participate}

This study was performed in line with the principles of the Declaration of Helsinki. Approval was granted by the Ethics Committee of University of Padova (HEC-DSB0617).

\section{Consent for publication}

Not applicable.

\section{Competing interests}

GMT serves as a consultant for a mobile phone application that assists users in implementing intermittent fasting programs. This consultancy consists of providing research-based information about the effects of intermittent fasting. The remaining authors declare that they have no competing interests.

\section{Author details}

${ }^{1}$ Department of Biomedical Science, University of Padova, Nutrition and Exercise Physiology Lab - Via Marzolo, 3, 35131 Padova, Italy. ${ }^{2}$ Department of Kinesiology \& Sport Management, Texas Tech University, Lubbock, TX, USA.

${ }^{3}$ Sport and Exercise Sciences Research Unit, University of Palermo, Palermo, Italy. ${ }^{4}$ Human Nutrition and Eating Disorder Research Center, Department of Public Health, Experimental and Forensic Medicine, University of Pavia, Pavia, Italy.

Received: 6 August 2020 Accepted: 7 December 2020

Published online: 11 December 2020

\section{References}

1. Waterhouse J. Effects of Ramadan on physical performance: chronobiological considerations. Br J Sports Med. 2010;44(7):509-15.

2. Anton SD, Moehl K, Donahoo WT, Marosi K, Lee SA, Mainous AG 3rd, et al. Flipping the metabolic switch: understanding and applying the health benefits of fasting. Obesity. 2018;26(2):254-68.

3. Paoli A, Tinsley G, Bianco A, Moro T. The influence of meal frequency and timing on health in humans: the role of fasting. Nutrients. 2019;11(4):719.

4. Meng H, Zhu L, Kord-Varkaneh H, Santos HO, Tinsley GM, Fu P. Effects of intermittent fasting and energy-restricted diets on lipid profile: a systematic review and meta-analysis. Nutrition. 2020;77:110801.

5. Trepanowski JF, Kroeger CM, Barnosky A, Klempel MC, Bhutani S, Hoddy KK, et al. Effect of alternate-day fasting on weight loss, weight maintenance, and cardioprotection among metabolically healthy obese adults: a randomized clinical trial. JAMA Intern Med. 2017;177(7):930-8.

6. Burke LM, King C. Ramadan fasting and the goals of sports nutrition around exercise. J Sports Sci. 2012;30(Suppl 1):S21-31.

7. Chaouachi A, Leiper JB, Chtourou H, Aziz AR, Chamari K. The effects of Ramadan intermittent fasting on athletic performance: recommendations for the maintenance of physical fitness. J Sports Sci. 2012;30(Suppl 1):S53-73. 
8. Abaïdia AE, Daab W, Bouzid MA. Effects of Ramadan fasting on physical performance: a systematic review with meta-analysis. Sports Med. 2020; 50(5):1009-26.

9. Schwellnus M, Soligard T, Alonso JM, Bahr R, Clarsen B, Dijkstra HP, et al. How much is too much? (Part 2) International Olympic Committee consensus statement on load in sport and risk of illness. Br J Sports Med. 2016;50(17):1043-52

10. Soligard T, Schwellnus M, Alonso JM, Bahr R, Clarsen B, Dijkstra HP, et al. How much is too much? (Part 1) International Olympic Committee consensus statement on load in sport and risk of injury. Br J Sports Med. 2016;50(17):1030-41.

11. Peake JM, Neubauer $O$, Walsh NP, Simpson RJ. Recovery of the immune system after exercise. J Appl Physiol. 2017;122(5):1077-87.

12. Pedersen BK, Rohde T, Ostrowski K. Recovery of the immune system after exercise. Acta Physiol Scand. 1998;162(3):325-32.

13. Nehlsen-Cannarella SL, Fagoaga OR, Nieman DC, Henson DA, Butterworth $\mathrm{DE}$, Schmitt RL, et al. Carbohydrate and the cytokine response to $2.5 \mathrm{~h}$ of running. J Appl Physiol. 1997;82(5):1662-7.

14. Nieman DC, Gillitt ND, Knab AM, Shanely RA, Pappan KL, Jin F, et al. Influence of a polyphenol-enriched protein powder on exercise-induced inflammation and oxidative stress in athletes: a randomized trial using a metabolomics approach. PLoS One. 2013;8(8):e72215.

15. Bermon S, Castell LM, Calder PC, Bishop NC, Blomstrand E, Mooren FC, et al. Consensus statement immunonutrition and exercise. Exerc Immunol Rev. 2017:23:8-50.

16. Drew MK, Vlahovich N, Hughes D, Appaneal R, Peterson K, Burke L, et al. A multifactorial evaluation of illness risk factors in athletes preparing for the summer Olympic games. J Sci Med Sport. 2017;20(8):745-50.

17. Drew M, Vlahovich $N$, Hughes D, Appaneal R, Burke LM, Lundy B, et al. Prevalence of illness, poor mental health and sleep quality and low energy availability prior to the 2016 summer Olympic games. Br J Sports Med. 2018; 52(1):47-53.

18. Longo VD, Mattson MP. Fasting: molecular mechanisms and clinical applications. Cell Metab. 2014;19(2):181-92.

19. Adawi M, Watad A, Brown S, Aazza K, Aazza H, Zouhir M, et al. Ramadan fasting exerts immunomodulatory effects: insights from a systematic review. Front Immunol. 2017:8:1144.

20. Tinsley GM, Forsse JS, Butler NK, Paoli A, Bane AA, La Bounty PM, et al. Time-restricted feeding in young men performing resistance training: a randomized controlled trial. Eur J Sport Sci. 2017;17(2):200-7.

21. Moro T, Tinsley G, Bianco A, Marcolin G, Pacelli QF, Battaglia G, et al. Effects of eight weeks of time-restricted feeding (16/8) on basal metabolism, maximal strength, body composition, inflammation, and cardiovascular risk factors in resistance-trained males. J Transl Med. 2016;14(1):290.

22. Tinsley GM, Moore ML, Graybeal AJ, Paoli A, Kim Y, Gonzales JU, et al. Timerestricted feeding plus resistance training in active females: a randomized trial. Am J Clin Nutr. 2019:110(3):628-40.

23. Hart PD. Test-retest stability of four common body composition assessments in college students. J Phys Fit Med Treat Sports. 2017;10.

24. WEIR JB. New methods for calculating metabolic rate with special reference to protein metabolism. J Physiol. 1949;109(1-2):1-9.

25. Toeller M, Buyken A, Heitkamp G, Milne R, Klischan A, Gries FA. Repeatability of three-day dietary records in the EURODIAB IDDM complications study. Eur J Clin Nutr. 1997;51(2):74-80.

26. Kerksick CM, Wilborn CD, Roberts MD, Smith-Ryan A, Kleiner SM, Jäger $R$, et al. ISSN exercise \& sports nutrition review update: research \& recommendations. J Int Soc Sports Nutr. 2018;15(1):38.

27. Vitale K, Getzin A. Nutrition and supplement update for the endurance athlete: review and recommendations. Nutrients. 2019;11(6):1289.

28. Gulcelik NE, Halil M, Ariogul S, Usman A. Adipocytokines and aging: adiponectin and leptin. Minerva Endocrinol. 2013;38(2):203-10.

29. Sull JW, Kim HJ, Yun JE, Kim G, Park EJ, Kim S, et al. Serum adiponectin is associated with family history of diabetes independently of obesity and insulin resistance in healthy Korean men and women. Eur J Endocrinol. 2009;160(1):39-43.

30. Hotta K, Funahashi T, Arita Y, Takahashi M, Matsuda M, Okamoto Y, et al. Plasma concentrations of a novel, adipose-specific protein, adiponectin, in type 2 diabetic patients. Arterioscler Thromb Vasc Biol. 2000;20(6):1595-9.

31. Zauner C, Schneeweiss B, Kranz A, Madl C, Ratheiser K, Kramer L, et al. Resting energy expenditure in short-term starvation is increased as a result of an increase in serum norepinephrine. Am J Clin Nutr. 2000;71(6):1511-5.
32. Muller MJ, Geisler C, Hubers M, Pourhassan M, Braun W, Bosy-Westphal A. Normalizing resting energy expenditure across the life course in humans: challenges and hopes. Eur J Clin Nutr. 2018;72(5):628-37.

33. Muller MJ, Enderle J, Pourhassan M, Braun W, Eggeling B, Lagerpusch $M$, et al. Metabolic adaptation to caloric restriction and subsequent refeeding: the Minnesota starvation experiment revisited. Am J Clin Nutr. 2015;102(4):807-19.

34. Rosenbaum M, Leibel RL. Models of energy homeostasis in response to maintenance of reduced body weight. Obesity (Silver Spring). 2016;24(8):1620-9.

35. Vollmers C, Gill S, DiTacchio L, Pulivarthy SR, Le HD, Panda S. Time of feeding and the intrinsic circadian clock drive rhythms in hepatic gene expression. Proc Natl Acad Sci U S A. 2009;106(50):21453-8.

36. Yasumoto $Y$, Hashimoto C, Nakao R, Yamazaki H, Hiroyama H, Nemoto T, et al. Short-term feeding at the wrong time is sufficient to desynchronize peripheral clocks and induce obesity with hyperphagia, physical inactivity and metabolic disorders in mice. Metabolism. 2016;65(5):714-27.

37. Röjdmark S. Increased gonadotropin responsiveness to gonadotropinreleasing hormone during fasting in normal subjects. Metabolism. 1987; 36(1):21-6.

38. Röjdmark S. Influence of short-term fasting on the pituitary-testicular axis in normal men. Horm Res. 1987:25(3):140-6.

39. Kajita K, Mune T, Ikeda T, Matsumoto M, Uno Y, Sugiyama C, et al. Effect of fasting on PPARgamma and AMPK activity in adipocytes. Diabetes Res Clin Pract. 2008:81(2):144-9.

40. Sponarova J, Mustard KJ, Horakova O, Flachs P, Rossmeisl M, Brauner P, et al. Involvement of AMP-activated protein kinase in fat depot-specific metabolic changes during starvation. FEBS Lett. 2005:579(27):6105-10.

41. Fontana L, Villareal DT, Das SK, Smith SR, Meydani SN, Pittas AG, et al. Effects of 2-year calorie restriction on circulating levels of IGF-1, IGF-binding proteins and cortisol in nonobese men and women: a randomized clinical trial. Aging Cell. 2016;15(1):22-7.

42. Chatard JC, Mujika I, Guy C, Lacour JR. Anaemia and iron deficiency in athletes. Practical recommendations for treatment. Sports Med. 1999;27(4): 229-40.

43. Lipschitz DA, Cook JD, Finch CA. A clinical evaluation of serum ferritin as an index of iron stores. N Engl J Med. 1974;290(22):1213-6.

44. Kaiser V, Janssen GM, van Wersch JW. Effect of training on red blood cell parameters and plasma ferritin: a transverse and a longitudinal approach. Int J Sports Med. 1989;10(Suppl 3):S169-75.

45. Horn PL, Pyne DB, Hopkins WG, Barnes CJ. Lower white blood cell counts in elite athletes training for highly aerobic sports. Eur J Appl Physiol. 2010; 110(5):925-32.

46. Walsh NP. Recommendations to maintain immune health in athletes. Eur J Sport Sci. 2018;18(6):820-31.

47. Svendsen IS, Taylor IM, Tønnessen E, Bahr R, Gleeson M. Training-related and competition-related risk factors for respiratory tract and gastrointestinal infections in elite cross-country skiers. Br J Sports Med. 2016:50(13):809-15.

48. Cerqueira É, Marinho DA, Neiva HP, Lourenço O. Inflammatory effects of high and moderate intensity exercise-a systematic review. Front Physiol. 2019;10:1550.

49. Tidball JG, Dorshkind $K$, Wehling-Henricks M. Shared signaling systems in myeloid cell-mediated muscle regeneration. Development. 2014;141(6):1184-96.

50. Moldoveanu Al, Shephard RJ, Shek PN. The cytokine response to physical activity and training. Sports Med. 2001;31(2):115-44.

51. Halberg N, Henriksen M, Söderhamn N, Stallknecht B, Ploug T, Schjerling P, et al. Effect of intermittent fasting and refeeding on insulin action in healthy men. J Appl Physiol. 2005;99(6):2128-36

52. Balta S, Celik T, Mikhailidis DP, Ozturk C, Demirkol S, Aparci M, et al. The relation between atherosclerosis and the neutrophil-lymphocyte ratio. Clin Appl Thromb Hemost. 2016;22(5):405-11.

53. Chen CY, Liao YH, Chou CC, Sung YC, Tsai SC. Initial systemic inflammatory state perturbs exercise training adaptations in elite taekwondo athletes. PLoS One. 2017;12(4):e0176140.

54. Walrand S, Moreau K, Caldefie F, Tridon A, Chassagne J, Portefaix G, et al. Specific and nonspecific immune responses to fasting and refeeding differ in healthy young adult and elderly persons. Am J Clin Nutr. 2001;74(5):670-8.

\section{Publisher's Note}

Springer Nature remains neutral with regard to jurisdictional claims in published maps and institutional affiliations. 